\title{
Insight into the gassing problem of Li-ion battery
}

\author{
Sheng S. Zhang* \\ Electrochemistry Branch, RDRLSED-C, Sensors and Electron Devices Directorate, U.S. Army Research Laboratory, Adelphi, MD, USA \\ *Correspondence: shengshui.zhang.civ@mail.mil; shengshui@gmail.com
}

Edited by:

Jie Xiao, Pacific Northwest National Laboratory, USA

Reviewed by:

Zonghai Chen, Argonne National Laboratory, USA

Xiao-Liang Wang, Seeo Inc., USA

Keywords: gas generation, battery swelling, performance degradation, high-voltage cathode, electrolyte additive, solid electrolyte interface

Gas generation (namely, the volume swelling of battery, or called the gassing) is a common phenomenon of the degradation of battery performance, which is generally a result of the electrolyte decomposition occurring during the entire lifespan of Li-ion batteries no matter whether the battery is in service or not. Abuse conditions such as overcharging and overheating make the gassing worse or even result in disastrous accidents. In overcharging, the gassing occurs mainly through the electrochemical oxidation of electrolyte solvents on the cathode with the $\mathrm{Li}^{+}$ions from the electrolyte being reduced into metallic $\mathrm{Li}$ on the anode. In overheating, the gassing takes place through not only the redox decomposition but also the chemical decomposition of the electrolyte solvents on both the anode and cathode besides the vapor expansion of volatile electrolyte solvents. In this opinion article, only the gas generation occurring under the normal operation and storage conditions will be addressed.

Assuming that the Li-ion battery is well formed in manufacture and properly operated in service, the gas generation can be attributed to the chemical decomposition and redox decomposition of the electrolyte solvents on the anode and cathode. The chemical decomposition of dialkyl carbonate solvents produces ether and $\mathrm{CO}_{2}$, as described by Eq. 1, which can take place on both the anode and cathode. Resulting $\mathrm{CO}_{2}$ can be reduced into $\mathrm{CO}$ in accompany with the consumption of $\mathrm{Li}^{+}$ions that are eventually originated from the cathode either by the chemical reduction (Eq. 2) or by the electrochemical reduction (Eq. 3) on the anode.

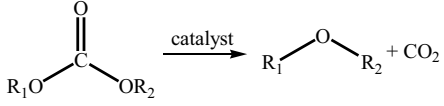

$$
\begin{aligned}
& \mathrm{CO}_{2}+2 \mathrm{LiC}_{6} \rightarrow \mathrm{Li}_{2} \mathrm{O}+\mathrm{C}_{6}+\mathrm{CO} \\
& \mathrm{CO}_{2}+2 \mathrm{Li}^{+}+2 \mathrm{e} \rightarrow \mathrm{Li}_{2} \mathrm{O}+\mathrm{CO}
\end{aligned}
$$

Therefore, $\mathrm{CO}_{2}$ and $\mathrm{CO}$ are often coexistent inside the battery. In particular, the chemical decomposition is increased with the temperature, and the redox decomposition is increased with the state-ofcharge (SOC) of battery. Chemical decomposition of the carbonate solvents is catalyzed by the anode, cathode, conducting carbon, and impurity particles, and lasts the entire lifespan of the Li-ion battery. Since a catalyst can be effectively deactivated by very small amounts of poisoning species, electrolyte additives appear to be very effective in suppressing the gas generation.

For the gas generation caused by the redox decomposition of electrolyte solvents on two electrodes, Figure 1 shows that the swelling ratio of a graphite/ $\mathrm{LiCoO}_{2}$ cell remains nearly constant when the SOC is lower than $80 \%$, however, dramatically increases as the SOC exceeds $80 \%$ (Lee et al., 2003). Potential-capacity profiles of the charging process indicate that the potential of the graphite anode is very flat at $\sim 0.25 \mathrm{~V}$ vs. $\mathrm{Li} / \mathrm{Li}^{+}$, whereas that of the $\mathrm{LiCoO}_{2}$ cathode linearly increases with the SOC (Zhang et al., 2006). This observation suggests that the gassing below $80 \%$ SOC can be attributed to the reduction of electrolyte solvents on the anode, and the increased gassing above $80 \%$ SOC to the oxidization of electrolyte solvents on the cathode. The redox-relative gas generation is closely associated with the anode and cathode materials, which are discussed below.

\section{ON ANODE}

The gases from the graphite anode are dominated by the reductive gases such as $\mathrm{H}_{2}, \mathrm{CO}$, olefins, and alkanes. The mildly oxidative $\mathrm{CO}_{2}$ is typically a product of the catalytic decomposition of carbonate solvents. The reduction of electrolyte solvents is considerably affected by the solid electrolyte interface (SEI) on the graphite surface, which is formed by the electrochemical reduction of the electrolyte solvents or additives at higher potentials than those of the intercalation of $\mathrm{Li}^{+}$ions into graphite. The gases generated during the formation of SEI have been degassed before the battery is sealed. Further gas generation is accompanied by the growth of SEI due to the parasitic solvent reduction or the failure of the pre-formed SEI. Therefore, forming a robust SEI is the key to the suppression of gas generation on the graphite based anode. It is in particular importance to note that the gassing from $\mathrm{Li}_{4} \mathrm{Ti}_{5} \mathrm{O}_{12}$ (LTO) anode is due to the intrinsic redox reaction between the LTO and carbonate solvents at the LTO-electrolyte interface (He et al., 2012). The redox reaction on one hand produces $\mathrm{H}_{2}, \mathrm{CO}$, and $\mathrm{CO}_{2}$, and on the other hand transforms the lattice structure of the LTO surface from (111) plane to (222) plane, resulting in the formation of a new $\mathrm{TiO}_{2}$ phase. Surface coating with nanoscale carbon particles shows very effective in suppressing the interfacial reaction and resultant gas generation from the LTO anode. 


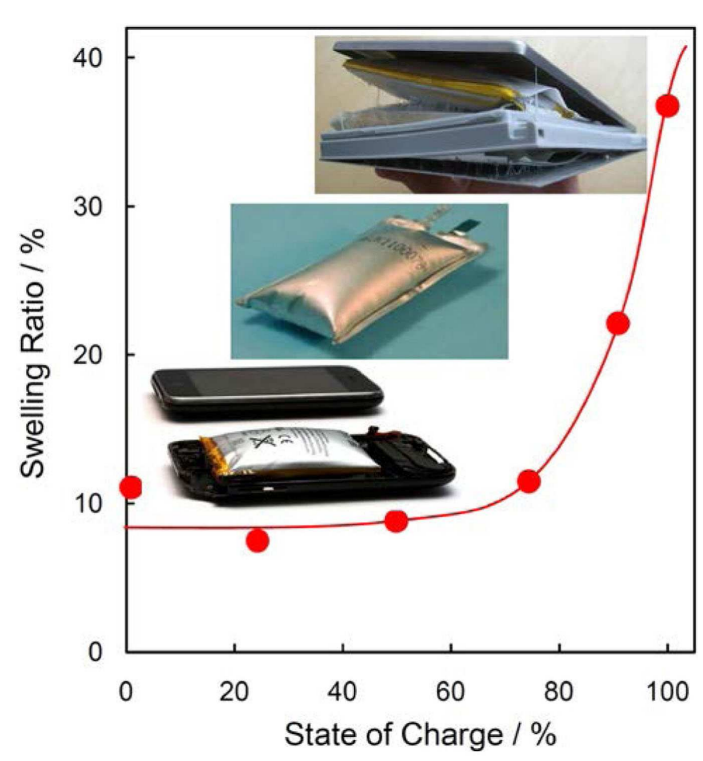

FIGURE 1 |A trend of swelling ratio with $\mathrm{SOC}$ for graphite/LiCoO ${ }_{2}$ prismatic cells stored at $90^{\circ} \mathrm{C}$ for $\mathbf{4} \mathbf{h}$. Drawn from the data of Lee et al. (2003).

\section{ON CATHODE}

The gases from the cathode are dominated by the mildly oxidative $\mathrm{CO}_{2}$, which can be produced by both the oxidative and chemical decompositions of the electrolyte solvents. Lithiated transition metal oxides are of very strong alkaline. Even a short period exposure to air, they will rapidly absorb $\mathrm{CO}_{2}$ and $\mathrm{H}_{2} \mathrm{O}$ to form $\mathrm{Li}_{2} \mathrm{CO}_{3}$ and $\mathrm{LiOH}$, resulting in the removal of $\mathrm{Li}^{+}$ions from the cathode particle surface, which changes not only the chemical composition but also the lattice structure of the cathode particle surface. Alkali metal carbonates $\left(\mathrm{M}_{2} \mathrm{CO}_{3}\right.$, $\mathrm{M}=\mathrm{K}, \mathrm{Na}$, and $\mathrm{Li}$ ) are a known catalyst for the direct synthesis of dialkyl carbonates from $\mathrm{CO}_{2}$ and alcohol (Yang et al., 2013). In the same principle, $\mathrm{Li}_{2} \mathrm{CO}_{3}$ on the cathode particle surface could catalyze and participate in the chemical decomposition of dialkyl carbonate solvents to generate $\mathrm{CO}_{2}$, as indicated by Eq. 4. Additionally, the $\mathrm{Li}_{2} \mathrm{CO}_{3}$ may react with $\mathrm{LiPF}_{6}$ from the electrolyte to produce $\mathrm{CO}_{2}$, as described by Eq. 5 .

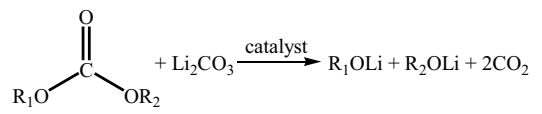

$$
\mathrm{Li}_{2} \mathrm{CO}_{3}+\mathrm{LiPF}_{6} \rightarrow 2 \mathrm{LiF}+\mathrm{LiPOF}_{4}+\mathrm{CO}_{2}
$$

As evidence for the above reactions, it is shown that the simple removal of $\mathrm{Li}_{2} \mathrm{CO}_{3}$ from the surface of $\mathrm{LiNi}_{0.83} \mathrm{Co}_{0.15} \mathrm{Al}_{0.02} \mathrm{O}_{2}$ cathode particles by washing with water can dramatically reduce the gassing of the cathode (Kim et al., 2006). In order to mitigate the gassing caused by the $\mathrm{Li}_{2} \mathrm{CO}_{3}$, the exposure to air should be maximally avoided in the storage of cathode materials as well as the coating and drying processes of the cathode sheets.

The other nature of the cathode materials is the dissolution of transition metal ions into the electrolyte solution (hereafter referred as to "metal dissolution" for simplicity) with the cycling and storage of Liion batteries, which was earliest ascribed to the HF-assisted disproportionation of $\mathrm{Mn}^{3+}$ ions for spinel $\mathrm{LiMn}_{2} \mathrm{O}_{4}$ cathode. In addition to those staying in the electrolyte solution, the dissolved metal ions are also incorporated into the SEI of two electrodes by combining with the solvent decomposition molecular moieties on the electrodes (both the cathode and the anode) or being reduced into the metal on the anode, leading to a rise in the SEI resistance ( $\mathrm{Xu}$, 2014). It is interesting to note that the metal dissolution is highly dependent of the SOC, showing a dramatic increase as the SOC approaches the end of charging (Terada et al., 2001; Pieczonka et al., 2013).
This finding reveals that the metal dissolution is also associated with the direct redox between the delithiated cathode material (for example, $\mathrm{MnO}_{2}$ for $\mathrm{LiMn}_{2} \mathrm{O}_{4}$ ) and electrolyte solvents. Comparison of the previous results (Terada et al., 2001; Lee et al., 2003) indicates an excellent corresponding correlation between the swellingSOC chart and the metal dissolution-SOC chart, suggesting that the metal dissolution must be accompanied by the gas generation. Therefore, the strategies for suppressing the metal dissolution are also applicable to the reduction of gas generation. The most effective suppression would be to coat the cathode with more stable compounds, such as, a metal oxide, a halide, a phosphate, and preferably a solid electrolyte (Li et al., 2013). Another benefit of the surface coating is to reduce the basicity of the cathode particle surface, which favors reducing $\mathrm{CO}_{2}$ absorption of the cathode and increasing chemical stability of the PVdF binder that is otherwise subject to dehydrofluorinate in strong alkaline environments (Dias and McCarthy, 1985). Besides the gassing caused by the $\mathrm{Li}_{2} \mathrm{CO}_{3}$ impurity and the metal dissolution, each type of cathode materials affects the gas generation in their specific manners, which are discussed, respectively, as below.

\section{LAYERED CATHODE MATERIALS}

The gassing from the layered cathode materials is mainly due to $\mathrm{O}_{2}$ evolution and metal dissolution. The layered cathode materials, such as $\mathrm{LiCoO}_{2}$, nickel-cobalt-aluminum (NCA), nickelmanganese-cobalt (NMC), and a family of Li-rich transition metal oxide solid solutions with a general formula of $x \mathrm{Li}_{2} \mathrm{MnO}_{3} \cdot(1-x) \mathrm{LiMO}_{2}(\mathrm{M}=\mathrm{Co}, \mathrm{Mn}$, $\mathrm{Ni})$, have no distinct potential rise that can be used to detect the fully charged state (i.e., the end of charging) by the battery charger. With the service going on, the impedance of the battery is progressively increased due to the growth of the SEI on the anode and cathode, which meanwhile consumes the $\mathrm{Li}^{+}$ions from the cathode. As a result, the capacity ratio of the cathode to anode is decreased so that the cathode can be readily overcharged if the charging protocol is not adjusted according to the real-time health of battery. Overcharging results in 
the evolution of $\mathrm{O}_{2}$, during which the oxygen radical anion intermediate can nucleophilically attack dialkyl carbonate solvents to produce $\mathrm{CO}_{2}$ and other insoluble products, as occurred in the Li-air batteries (Freunberger et al., 2011), with the insoluble products further contributing to the growth of resistive SEI on the cathode. The $\mathrm{O}_{2}$ evolution results in a net loss of $\mathrm{Li}_{2} \mathrm{O}$, and consequently changes the lattice structure of the cathode materials, as described by Eq. 6:

$$
\begin{aligned}
& \mathrm{Li}_{\mathrm{X}} \mathrm{MO}_{2}-4 \delta \mathrm{e}^{-} \rightarrow \mathrm{Li}_{\mathrm{X}-4 \delta} \mathrm{MO}_{2-2 \delta} \\
& +4 \delta \mathrm{Li}^{+}+\delta \mathrm{O}_{2}
\end{aligned}
$$

Since " $4 \delta \mathrm{Li}^{+}+\delta \mathrm{O}_{2}$ " in the product side of Eq. 6 is equivalent to " $2 \delta \mathrm{Li}_{2} \mathrm{O}-4 \delta \mathrm{e}^{-}$," the net result of the $\mathrm{O}_{2}$ evolution is a loss of $\mathrm{Li}_{2} \mathrm{O}$. In accompany with the $\mathrm{O}_{2}$ evolution, the released $\mathrm{Li}^{+}$ions are incorporated into the SEI of the cathode, which results in the growth of the cathode SEI and contributes to the irreversible overcharging capacity. Therefore, the $\mathrm{O}_{2}$ evolution caused by overcharging is the source of not only the gas generation but also the SEI growth on the cathode. In particular, charging potentials of the Li-rich $x \mathrm{Li}_{2} \mathrm{MnO}_{3} \cdot(1-x) \mathrm{LiMO}_{2}$ $(\mathrm{M}=\mathrm{Co}, \mathrm{Mn}, \mathrm{Ni})$ solid solutions are up to above $4.6 \mathrm{~V}$ vs. $\mathrm{Li} / \mathrm{Li}^{+}$. Even in normal operation potential range $(2.0-4.6 \mathrm{~V})$, the $\mathrm{O}_{2}$ evolution is inevitable, leading to an irreversible lattice structural transformation of the cathode materials (Armstrong et al., 2006; Gu et al., 2013). The $\mathrm{O}_{2}$ evolution and resulting reactions with the carbonate solvents and even with the conducting carbon agent (i.e., oxidation in the latter case) have been recognized to be the major cause for the gas generation and capacity degradation of the Li-rich cathode materials. Therefore, timely adjusting of the charging protocol to strictly avoid the overcharging and structural stabilization by doping with more stable metal ions such as $\mathrm{Al}^{3+}$ would be very effective to suppress the gas generation from the layered cathode materials.

\section{SPINEL CATHODE MATERIALS}

The gassing from the spinel cathode materials, such as $4 \mathrm{~V} \mathrm{L_{2 }} \mathrm{Mn}_{2} \mathrm{O}_{4}$ and $4.7 \mathrm{~V}$ $\mathrm{LiNi}_{0.5} \mathrm{Mn}_{1.5} \mathrm{O}_{4}$, is dominated by the oxidation of the electrolyte solvents. The ultimate products of the oxidation of carbonate solvents are $\mathrm{CO}_{2}$ and $\mathrm{H}_{2} \mathrm{O}$, and organic acids $\left(\mathrm{H}^{+}\right)$are the possible intermediate of the solvent oxidization (Armstrong et al., 2005). Therefore, the oxidation very likely initiates other problems, such as the hydrolysis of $\mathrm{LiPF}_{6}$ salt and $\mathrm{H}_{2}$ generation as the $\mathrm{H}_{2} \mathrm{O}$ and organic acid intermediate are diffused onto the anode and reduced there. The electrochemical oxidation occurs only in the charging process, whereas the chemical oxidation lasts the entire lifespan and it is often accompanied by the metal dissolution. Surface coating with more robust compounds such as $\mathrm{AlPO}_{4}, \mathrm{AlF}_{3}, \mathrm{Al}_{2} \mathrm{O}_{3}, \mathrm{ZnO}$, $\mathrm{Bi}_{2} \mathrm{O}_{3}$ (Liu and Manthiram, 2009), and solid electrolyte (Li et al., 2013) shows very effective in suppressing the metal dissolution, this strategy is certainly applicable to the gassing reduction. Lithium bis(oxalato)borate ( $\mathrm{LiBOB}$ ) is very effective in suppressing metal dissolution, however, it is oxidized to generate $\mathrm{CO}_{2}$ at high potentials. Some electrolyte additives, such as fluorinated carbonates (Zhang et al., 2013) and phosphates (Cresce and Xu, 2011), have the ability to form robust SEI on the cathode surface by the chemical reaction, and hence could offer an alternative approach for the in situ surface coating to protect the $4.7 \mathrm{~V} \mathrm{LiNi}_{0.5} \mathrm{Mn}_{1.5} \mathrm{O}_{4}$ cathode from direct contact with the liquid electrolyte. The above approaches are also applicable to the other high-voltage cathode materials such as Li-rich layered oxides and $\mathrm{LiCoPO}_{4}$. For the $\mathrm{LiNi}_{0.5} \mathrm{Mn}_{1.5} \mathrm{O}_{4}$ cathode, the $\mathrm{Li}_{x} \mathrm{Ni}_{1-x} \mathrm{O}$ impurity is also responsible for the gas generation because above $4.5 \mathrm{~V}$ vs. $\mathrm{Li} / \mathrm{Li}^{+}$it evolves $\mathrm{O}_{2}$, during which the oxygen radical anion intermediate reacts with the carbonate solvents to produce $\mathrm{CO}_{2}$. A combination of the surface coating, using electrolyte additive and purifying cathode material likely leads to a synergistic effect for the gassing suppression of the high-voltage $\mathrm{LiNi}_{0.5} \mathrm{Mn}_{1.5} \mathrm{O}_{4}$ cathode.

In summary, gas generation in the Liion batteries involves many complicated reactions in relation to the chemical and redox decompositions of the electrolyte solvents. The chemical decomposition is catalyzed by the active electrode materials, conducting carbon, and $\mathrm{Li}_{2} \mathrm{CO}_{3}$ impurity. The redox decomposition may be an electrochemical process or/and a chemical process, in which the former occurs only in the charging process, whereas the latter lasts the entire lifespan of the battery and is often accompanied by the metal dissolution. The dissolved metal ions participate in the progressive formation of SEI on the cathode and anode, resulting in the growth of the resistive SEI and adversely affecting the performance of the Li-ion batteries. Given that all the materials are in high purity and are strictly dried, the combination of the surface coating and electrolyte additive would offer the most effective solution to the gassing problem of Li-ion batteries.

\section{ACKNOWLEDGMENTS}

The author thanks Dr. C. Lundgren for her critical reading of the manuscript and valuable suggestions.

\section{REFERENCES}

Armstrong, A. R., Holzapfel, M., Novak, P., Johnson, C. S., Kang, S. H., Thackeray, M. M., et al. (2006). Demonstrating oxygen loss and associated structural reorganization in the lithium battery cathode $\mathrm{Li}\left[\mathrm{Ni}_{0.2} \mathrm{Li}_{0.2} \mathrm{Mn}_{0.6}\right] \mathrm{O}_{2}$. J. Am. Chem. Soc. 128, 8694-8698. doi:10.1021/ja062027+

Armstrong, A. R., Robertson, A. D., and Bruce, P. G. (2005). Overcharging manganese oxides: extracting lithium beyond $\mathrm{Mn}^{4+}$. J. Power Sources 146, 275-280. doi:10.1016/j.jpowsour.2005.03.104

Cresce, A. V., and Xu, K. (2011). Electrolyte additive in support of $5 \mathrm{~V} \mathrm{Li}$ ion chemistry. J. Electrochem. Soc. 158, A337-A342. doi:10.1149/1.3532047

Dias, A. J., and McCarthy, T. J. (1985). Dehydrofluorination of poly(vinylidene fluoride) in dimethylformamide solution: synthesis of an operationally soluble semiconducting polymer. J. Polym. Sci. A Polym. Chem. 23, 1057-1061. doi:10.1002/pol. 1985.170230410

Freunberger, S. A., Chen, Y., Peng, Z., Griffin, J. M., Hardwick, L. J., Barde, F., et al. (2011). Reactions in the rechargeable lithium- $\mathrm{O}_{2}$ battery with alkyl carbonate electrolytes. J. Am. Chem. Soc. 133, 8040-8047. doi:10.1021/ja2021747

Gu, M., Belharouak, I., Zheng, J., Wu, H., Xiao, J., Genc, A., et al. (2013). Formation of the spinel phase in the layered composite cathode used in $\mathrm{Li}$ ion batteries. ACS Nano 7, 760-767. doi:10.1021/ nn305065u

He, Y. B., Li, B., Liu, M., Zhang, C., Lv, W., Yang, C., et al. (2012). Gassing in $\mathrm{Li}_{4} \mathrm{Ti}_{5} \mathrm{O}_{12}$-based batteries and its remedy. Sci. Rep. 2, 913. doi:10.1038/srep00913

Kim, J., Hong, Y., Ryu, K. S., Kim, M. G., and Cho, J. (2006). Washing effect of a $\mathrm{LiNi}_{0.83} \mathrm{Co}_{0.15} \mathrm{Al}_{0.02} \mathrm{O}_{2}$ cathode in water. Electrochem. Solid State Lett. 9, A19-A23. doi:10.1149/1.2135427

Lee, K. H., Song, E., and Lim, H. S. (2003). "Swelling mechanism of the lithium ion battery at high temperature," in 203rd ECS Meeting, Abs. \#110 (Paris). Available at: https://www.electrochem.org/dl/ma/ 203/pdfs/0110.pdf

Li, J., Baggetto, L., Martha, S. K., Veith, G. M., Nanda, J., Liang, C., et al. (2013). An artificial solid electrolyte interphase enables the use of a $\mathrm{LiNi}_{0.5} \mathrm{Mn}_{1.5} \mathrm{O}_{4} 5 \mathrm{~V}$ 
cathode with conventional electrolytes. Adv. Energy Mater. 3, 1275-1278. doi:10.1002/aenm201300378

Liu, J., and Manthiram, A. (2009). Understanding the improvement in the electrochemical properties of surface modified $5 \mathrm{~V} \mathrm{LiMn}{ }_{1.42} \mathrm{Ni}_{0.42} \mathrm{Co}_{0.16} \mathrm{O}_{4}$ spinel cathodes in lithium-ion cells. Chem. Mater. 21, 1695-1707. doi:10.1021/cm9000043

Pieczonka, N. P. W., Liu, Z., Lu, P., Olson, K. L., Moote, J., Powell, B. R., et al. (2013). Understanding transition-metal dissolution behavior in $\mathrm{LiNi}_{0.5} \mathrm{Mn}_{1.5} \mathrm{O}_{4}$ high-voltage spinel for lithium ion batteries. J. Phys. Chem. C 117, 15947-15957. doi:10.1021/jp405158m

Terada, Y., Nishiwaki, Y., Nakai, I., and Nishikawa, F. (2001). Study of $\mathrm{Mn}$ dissolution from $\mathrm{LiMn}_{2} \mathrm{O}_{4}$ spinel electrodes using in situ total reflection X-ray fluorescence analysis and fluorescence XAFS technique. J. Power Sources 9, 420-422. doi:10.1016/ S0378-7753(01)00741-8
$\mathrm{Xu}, \mathrm{K}$. (2014). Electrolytes and interphases in Liion batteries and beyond. Chem. Rev. doi:10.1021/ cr500003w

Yang, Q., Wang, H., Ding, X., Yang, X., and Wang, Y. (2013). One-pot synthesis of dimethyl carbonate from carbon dioxide, cyclohexene oxide, and methanol. Res. Chem. Intermed. 1-11. doi:10.1007/ s11164-013-1514-4

Zhang, S. S., Xu, K., and Jow, T. R. (2006). Study of the charging process of a $\mathrm{LiCoO}_{2}$-based $\mathrm{Li}$-ion battery. J. Power Sources 160, 1349-1354. doi:10. 1016/j.jpowsour.2006.02.087

Zhang, Z., Hu, L., Wu, H., Weng, W., Koh, M., Redfern, P. C., et al. (2013). Fluorinated electrolytes for $5 \mathrm{~V}$ lithium-ion battery chemistry. Energy Environ. Sci. 6, 1806-1810. doi:10.1039/C3EE24414H

Conflict of Interest Statement: The author declares that the research was conducted in the absence of any commercial or financial relationships that could be construed as a potential conflict of interest.

Received: 03 November 2014; accepted: 18 November 2014; published online: 05 December 2014.

Citation: Zhang SS (2014) Insight into the gassing problem of Li-ion battery. Front. Energy Res. 2:59. doi: 10.3389/fenrg.2014.00059

This article was submitted to Energy Storage, a section of the journal Frontiers in Energy Research.

Copyright (c) 2014 Zhang. This is an open-access article distributed under the terms of the Creative Commons Attribution License (CC BY). The use, distribution or reproduction in other forums is permitted, provided the original author(s) or licensor are credited and that the original publication in this journal is cited, in accordance with accepted academic practice. No use, distribution or reproduction is permitted which does not comply with these terms. 